\title{
An MRI study on the relations between muscle atrophy, shoulder function and glenohumeral deformity in shoulders of children with obstetric brachial plexus injury
}

\author{
Valerie $\mathrm{M}$ van Gelein Vitringa ${ }^{1}$, Ed $\mathrm{O}$ van Kooten ${ }^{2}$, Richard T Jaspers ${ }^{3}$, \\ Margriet G Mullender ${ }^{1}$, Mirjam H van Doorn-Loogman ${ }^{4}$ and Johannes A van \\ der Sluijs*1
}

Address: ${ }^{1}$ Department of Orthopaedic Surgery, VU medical center, 1007 MB, Amsterdam, The Netherlands, ${ }^{2}$ Department of Plastic and Reconstructive Surgery, VU medical center, $1007 \mathrm{MB}$, Amsterdam, The Netherlands, ${ }^{3}$ Research Institute MOVE, Faculty of Human Movement Science, VU University Amsterdam, 1081 BT, Amsterdam, The Netherlands and ${ }^{4}$ Department of Rehabilitation, VU Medical Center, 1007 MB, Amsterdam, The Netherlands

Email: Valerie M van Gelein Vitringa - valerievgv@hotmail.com; Ed O van Kooten - E.vanKooten@vumc.nl; Richard T Jaspers - r.jaspers@fbw.vu.nl; Margriet G Mullender - m.mullender@vumc.nl; Mirjam H van DoornLoogman - MH.vanDoorn@vumc.nl; Johannes A van der Sluijs* - ja.vandersluijs@vumc.nl

* Corresponding author

This article is available from: http://www.jbppni.com/content/4/I/9

(C) 2009 van Gelein Vitringa et al; licensee BioMed Central Ltd.

This is an Open Access article distributed under the terms of the Creative Commons Attribution License (http://creativecommons.org/licenses/by/2.0), which permits unrestricted use, distribution, and reproduction in any medium, provided the original work is properly cited.

\section{Correction}

After publication of this work [1], we noted that we inadvertently failed to include the complete list of all coauthors. The full list of authors has now been added and the Authors' contributions and Competing interests sections modified accordingly.

\section{Competing interests}

The authors declare that they have no competing interests.

\section{Authors' contributions}

VMvGV, RTJ and JAvdS did design, data acquisition, analysis, and writing. EOvK MM and MHVD revised the manuscript critically for important intellectual content. All authors approved the final version.

\section{References}

I. van Gelein Vitringa VM, van Kooten EO, Mullender MG, van DoornLoogman MH, Sluijs JA van der: An MRI study on the relations between muscle atrophy, shoulder function and glenohumeral deformity in shoulders of children with obstetric brachial plexus injury. J Brachial Plex Peripher Nerve Inj 2009, 4:5. 